\title{
Optical and electrical properties of nickel xanthate thin films
}

\author{
I A KARIPER ${ }^{1, *}$ and T ÖZPOZAN ${ }^{2}$ \\ ${ }^{1}$ Education Faculty, ${ }^{2}$ Faculty of Art and Science, Erciyes University, 38039 Kayseri, Turkey
}

MS received 8 January 2013; revised 11 March 2013

\begin{abstract}
Nickel xanthate thin films (NXTF) were successfully deposited by chemical bath deposition, on to amorphous glass substrates, as well as on $\boldsymbol{p}$ - and $\boldsymbol{n}$-silicon, indium tin oxide and poly(methyl methacrylate). The structure of the films was analysed by X-ray diffraction (XRD), far-infrared spectrum (FIR), mid-infrared (MIR) spectrum, nuclear magnetic resonance (NMR) and scanning electron microscopy (SEM). These films were investigated from their structural, optical and electrical properties point of view. Uniform distribution of grains was clearly observed from the photographs taken by scanning electron microscope (SEM). The higher transmittance was about 50-60\% after optimizing the parameters of deposition time and temperature $\left(4 \mathrm{~h}, 50{ }^{\circ} \mathrm{C}\right)$. The optical bandgap of the NXTF was graphically estimated as 3.90-3.96 eV. The resistivity of the films was calculated as $62 \cdot 6-90.7 \Omega \cdot \mathrm{cm}$ on commercial glass depending on the film thickness and $62 \cdot 2-74.5 \Omega \cdot \mathrm{cm}$ on the other substrates. The MIR and FIR spectra of the films conformed to the literature and their solid powder forms. The expected peaks of nickel xanthate were observed in NMR analysis on glass. The films were dipped into chloroform as organic solvent and were analysed by NMR.
\end{abstract}

Keywords. Nickel xanthate thin film; organometallic thin film; chemical bath deposition.

\section{Introduction}

Organometallic thin films have given rise to new technologies. These organometallic compounds have a wide range of properties such as optical, electrical and magnetic characteristics. It has been shown that these thin films show different properties such as an antibacterial agent, magnetic and semi-conductor material, which allowed them to be used for data storage, solar cell production, water purification, etc. (Gao et al 1997; Fischer et al 1998; Grassi et al 2004; Musetha 2006; Reyes and Teplyakov 2007; Jeong et al 2009). Xanthates are also very useful chemicals that are utilized in many areas and sectors (Leja 1982; Zohir et al 2009). Neither xanthate and metal-xanthate thin films' production, nor their optical, electrical properties and structural analysis have been studied yet. These thin films and their bulk production may be useful in many areas, especially in solar cell manufacturing. Some thin film deposition methods, such as chemical vapour deposition, and physical vapour deposition have been used to produce metal sulfide thin film (Hitchman and Jensen 1993; Musetha 2006). On the other hand, these methods are expensive and need a variety of instruments unlike the chemical bath deposition method.

Metal xanthate complexes rapidly occur when the precipitate rises to the surface in chemical bath deposition. Moreover, due to the nature of organometallic thin films,

*Author for correspondence (akariper@gmail) it is difficult to analyse them. The metal xanthate thin films were produced with difficulty. The producing of metal xanthate thin films is very important point. The aim of this study is to produce nickel xanthate thin film by chemical bath deposition and to examine its structural, optical and electrical properties.

\section{Experimental}

\subsection{Reagents}

Isopropyl xanthate was synthesized in line with the literature (Wilhelm 1929, 1935; Wilhelm et al 1935; Ruffle et al 1953; McCool 1954; Valdivieso et al 2006), and the stock solution of $0.1 \mathrm{M}$ was prepared. High purity reagents were used for all the prepared solutions. The stock solution was diluted each time when required.

The other stock solution of nickel nitrate salt was prepared from high purity compound $(99.9 \%$, E Merck, Darmstadt, Sigma Aldrich). All laboratory glassware and substrates were cleaned by soaking in diluted nitric acid, and rinsing with alcohol and deionized water prior to use. The substrates were also cleaned and dipped into $\mathrm{HNO}_{3}$ and alcohol.

\subsection{Synthesis of isopropyl xanthate}

Isopropyl xanthate was synthesized by dissolving $3.74 \mathrm{~g}$

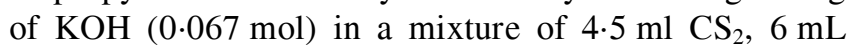


isopropyl alcohol and $9 \mathrm{~mL}$ benzene and heated under a reflux condenser. The mixture was mixed for $20 \mathrm{~min}$ at $35^{\circ} \mathrm{C}$ and for $45 \mathrm{~min}$ at $45^{\circ} \mathrm{C}$. Then, it was mixed for $1 \mathrm{~h}$ at $60{ }^{\circ} \mathrm{C}$. Approximately $9 \mathrm{~g}$ of the reaction product was then purified by rinsing with acetone and drying in the oven at $30^{\circ} \mathrm{C}$ for $48 \mathrm{~h}$ (Pellizzeti and Pramauro 1985; Laespada et al 1993; Pramauro and Prevot 1995; Manzoori and Bavili-Tabrizi 2002; Paleologos et al 2002; Stalikas 2002; Armitage 2004; Miller et al 2005; Bertram and Bodmeier 2006; Ghaedi 2007; Rubio et al 2007; Fehér et al 2008).

\subsection{Preparation of films}

$10 \mathrm{~mL} 0 \cdot 1 \mathrm{M} \mathrm{Ni}\left(\mathrm{NO}_{3}\right)_{2} \cdot 6 \mathrm{H}_{2} \mathrm{O}$ and $10 \mathrm{~mL} 0 \cdot 1 \mathrm{M}$ isopropyl xanthate were mixed in a beaker. The substrates were dipped into this chemical bath at required temperatures. As a result of ion-ion mechanism, NXTF was formed and was deposited on all the substrates. The films were deposited at different temperatures of 30,40 and $50{ }^{\circ} \mathrm{C}$, whereas $\mathrm{pH}$ of the bath was 6.50. In addition, deposition time was changed from 4 to $7 \mathrm{~h}$ at 40 and $50{ }^{\circ} \mathrm{C}, 16-19 \mathrm{~h}$ at $30^{\circ} \mathrm{C}$. The thin films were cleaned in purified water and dried before their further examinations.

\subsection{Measurements}

The crystalline structure of the NXTF was confirmed by $\mathrm{X}$-ray diffraction (XRD) which has a $\mathrm{CuK} \alpha_{1}$ radiation source (Rikagu RadB model, $\lambda=1.5406 \AA$ ) over the range $10^{\circ}<2 \theta<70^{\circ}$ at a speed of $3^{\circ} \mathrm{min}^{-1}$ with a step size of $0.02^{\circ}$. The infrared spectrum of NXTF was recorded by a Perkin Elmer Spectrum 400 spectrometer with a resolution of $4 \mathrm{~cm}^{-1}$ using DTGS detector and 10 scans for each spectrum. The ${ }^{1} \mathrm{H}-\mathrm{NMR}$ spectra were measured by a Bruker $(400 \mathrm{MHz})$ spectrometer with 16 scans of each measurement. The surface properties of all the films were examined using an EVO40-LEO computer controlled digital scanning electron microscope (SEM) with a secondary electron detector. Electrical properties were measured using four point measurements technique and accordingly the resistivity was calculated. The optical measurements were conducted by a Hach Lange DR $5000 \mathrm{UV}-\mathrm{Vis}$ spectrophotometer at room temperature by placing an uncoated identical glass substrate in the reference beam. The optical spectra of the thin films were recorded in the wavelength range of 300-1100 nm. The film thicknesses were measured with a Veeco Multi Mode AFM (Controller = NanoScope 3D). Thicknesses were measured in a $10 \times 10 \mu \mathrm{m}$ area with tapping mode.

\section{Results and discussion}

As shown in figure 1, an X-ray diffraction study was carried out at room temperature. The peaks of the XRD pattern show the formation of the single phase, which is nickel xanthate, with an orthorhombic structure. The lattice parameters were $a=15.8504 \AA, b=11.0537 \AA$, $c=10.4612 \AA$ and angles $\alpha=90^{\circ}, \beta=90^{\circ}, \gamma=90^{\circ}$ (Cullity 1967; Zelmon et al 1998; Haiduc et al 2003; Musetha 2006). The location of atoms in the plane is displayed in figure 1.

We also used FIR, MIR and NMR to compare nickel xanthate thin film on glass with nickel xanthate solid powder, which is shown in figures 2-4.

In figures 2 and 3, no change has been observed in the FIR and MIR spectra of nickel xanthate solid powder and nickel xanthate thin film.

Figure 2 illustrates that in the nickel xanthate solid powder and thin film (MIR): (i) the asymmetric and symmetric stretching vibration of the aliphatic group $\left(-\mathrm{CH}_{3}\right)$ was seen at 2977-2930-2849 $\mathrm{cm}^{-1}$, (ii) the bending vibration of $-\mathrm{CH}_{3}$ was seen at 1446-1447-1375-1354$1331 \mathrm{~cm}^{-1}$, (iii) the asymmetric stretching vibration of C-O-C at $1269-1183-1143 \mathrm{~cm}^{-1}$, (iv) the symmetrical stretching vibration of $-\mathrm{C}-\mathrm{O}$ at $1079 \mathrm{~cm}^{-1}$, (v) the rocking vibration of $-\mathrm{CH}_{3}$ at $1012-996 \mathrm{~cm}^{-1}$, (vi) the rocking vibration of $-\mathrm{CH}_{3}$ at $894 \mathrm{~cm}^{-1}$, (vii) the symmetric bending vibration of $\mathrm{C}-\mathrm{O}-\mathrm{C}$ at $458 \mathrm{~cm}^{-1}$.

In figure 3 , the stretching vibrations of $\mathrm{Ni}-\mathrm{S}$ are also observed at $353 \mathrm{~cm}^{-1}$ and in the other organic groups of nickel xanthate (Shankaranarayana and Patel 1961; Watt and McCormick 1965; Cristol and Seapy 1982; Fornasiero et al 1995; Xu and Ding 2004; Erdik et al 2007;

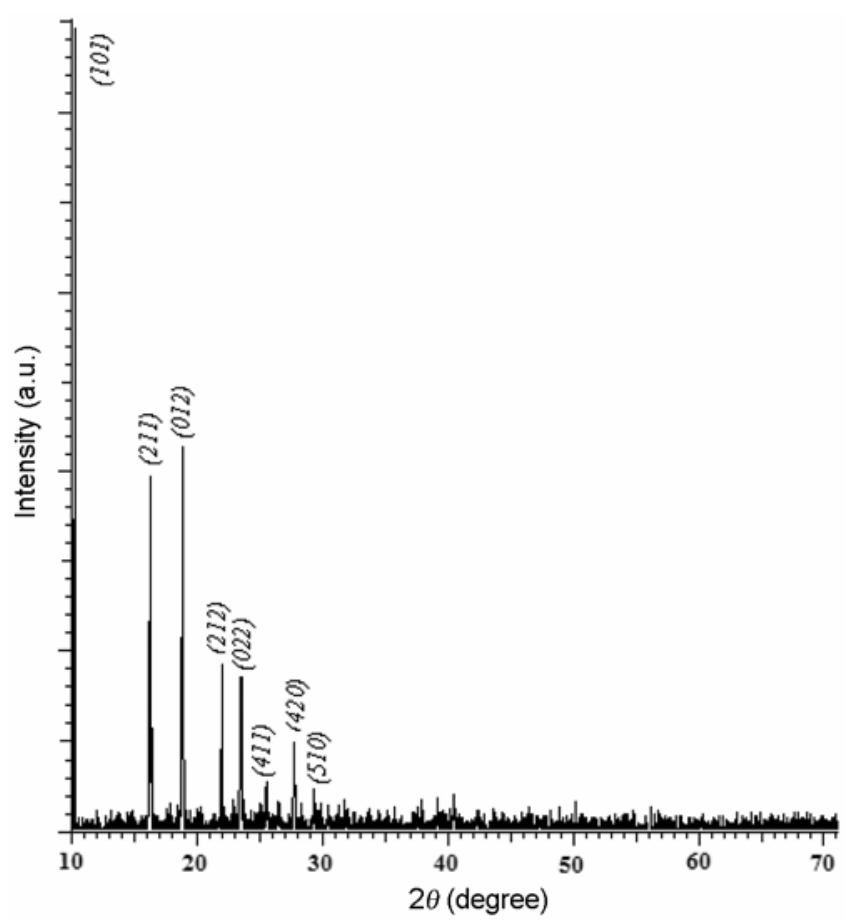

Figure 1. X-ray diffraction patterns of NXTF deposited on glass substrate. 


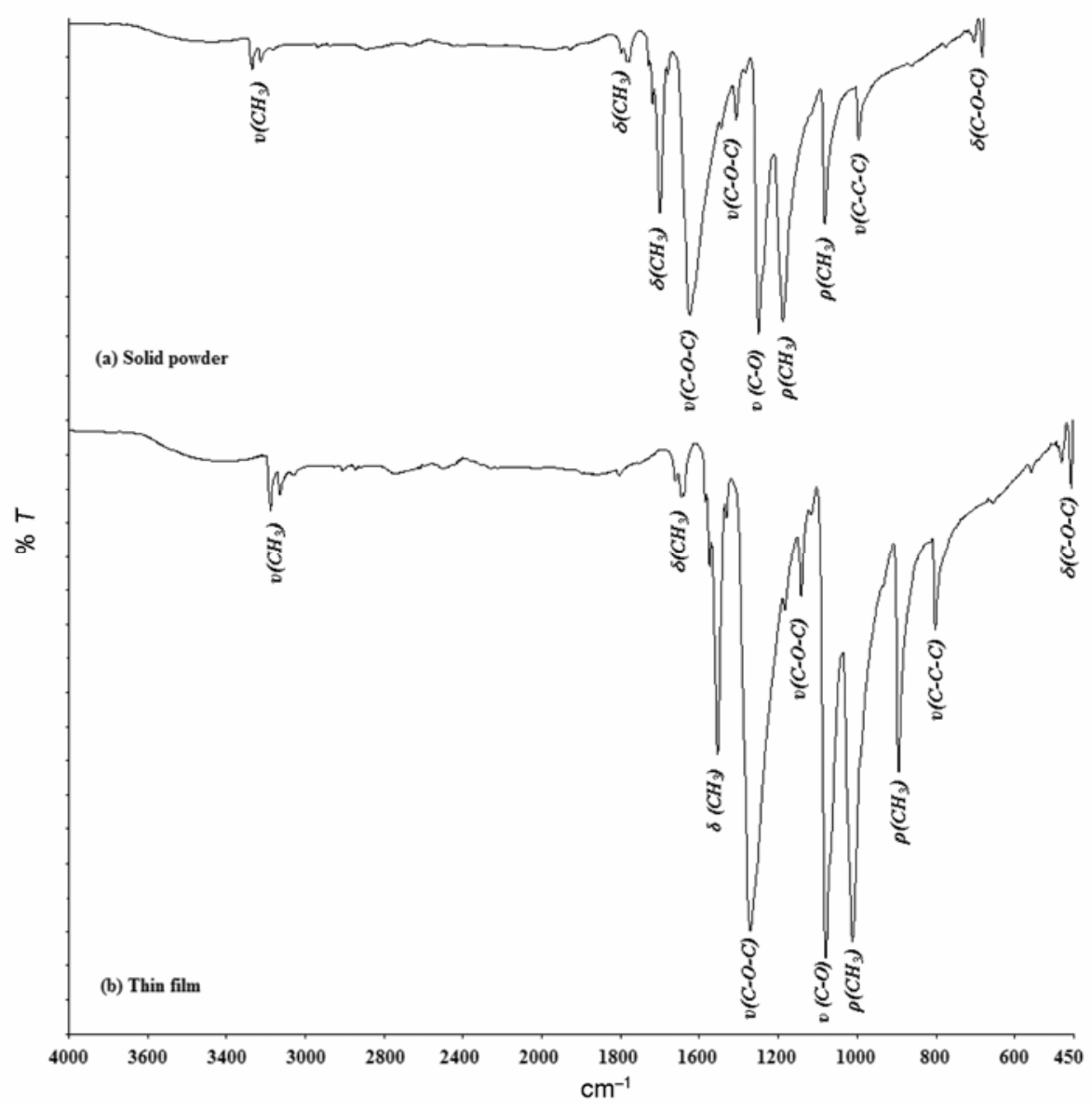

Figure 2. Nickel xanthate MIR spectrum of (a) solid powder and (b) thin film on glass substrate.

Zohir et al 2009). We did not consider measurements below $200 \mathrm{~cm}^{-1}$. Some NXTF peaks did not show spectra in thin film because thin film's grains were in nano scale.

Figure 3 illustrates that in the nickel xanthate solid powder and thin film (FIR): (i) the stretching vibration of $-\mathrm{C}-\mathrm{S}$ at $690-647-564 \mathrm{~cm}^{-1}$, (ii) the bending vibration of $\mathrm{C}-\mathrm{O}-\mathrm{C}$ at $466-443 \mathrm{~cm}^{-1}$, (iii) the bending vibration of $\mathrm{C}-\mathrm{C}-\mathrm{O}$ at $384 \mathrm{~cm}^{-1}$, the bending vibration of $\mathrm{O}-\mathrm{C}-\mathrm{S}$ at $302 \mathrm{~cm}^{-1}$, (iv) the bending vibration of $\mathrm{S}-\mathrm{C}-\mathrm{S}$ at $234 \mathrm{~cm}^{-1}$.

In ${ }^{1} \mathrm{H}-\mathrm{NMR}$ spectrum (in figure 4), NXTF was dipped into a chloroform solution to analyse the spectrum. The scanning number of all the samples was 16 . The solvent peak (chloroform) was observed at $7.2 \mathrm{ppm}$ and the trace concentration of the water peak was observed at $1.5 \mathrm{ppm}$, whereas the doublet peak of the $-\mathrm{CH}_{3}$ group occurred at 1.42 and $1.47 \mathrm{ppm}$. Since the proton number was six, the integration number was $6 \cdot 17$. The group of $-\mathrm{CH}$ NMR peaks was divided into five between 5.50-5.30 due to the neighboring $-\mathrm{CH}_{3}$ groups, whose integration number was 1.00. The $-\mathrm{CH}$ group had an oxygen atom as a neighbour which caused a decreased electron shielding, so its peak was observed in the low area (Taş 2003; Ivanov 2004; Sahar et al 2004; Oliveria and Rubio 2009). No impurity was observed in the spectra (unknown or not related peaks). A literature review revealed that there are not many studies about nickel xanthate in the literature and the most enlightening one has been conducted by Görgülü (2002). Görgülü (2002), mostly worked on the infrared spectrum of the xanthate complexes that was formed with the metals. Although, he has stated that the strongest and sharpest peaks were observed on $-\mathrm{OH}$ and $-\mathrm{CH}$ aliphatic groups, we did not notice -OH peaks in our study (they were ignored since they were very weak peaks), on the other hand - $\mathrm{CO}$ symmetric vibrations have given drastically strong peaks in addition to aliphatic groups. The reason behind it, is that he has selected tertiary amine derivatives as the base of the xanthate, whereas we preferred isopropyl structure, which is simpler (Görgülü 2002). But both of us were able to synthesize green coloured nickel xanthates. In his ${ }^{1} \mathrm{H}-\mathrm{NMR}$ analysis, he observed $\mathrm{NCH}_{2}$ doublet peaks at $2.65 \mathrm{ppm}$ due to the electronegativity of the nitrogen atom of the xanthate with which he was working; in addition, he also observed pentad peaks at $5.75 \mathrm{ppm}$. NMR and IR results of this study are mostly in line with the literature.

The transmittance $(T)$ and absorbance $(A)$ for NXTF can be used for the calculation of reflectance $(R)$ from the following expression (Benramdane et al 1997): 


$$
T=(1-R)^{2} e^{-A} .
$$

Transmittance and absorbance measurements were performed at room temperature in the range of 300$1100 \mathrm{~nm}$. The films were deposited at different deposition temperatures and deposition times as shown in figure 5. The transmittance change with changing deposition times and deposition temperatures can be seen from the curves. The optimum values for deposition time and temperature were selected as $4 \mathrm{~h}$ at $50^{\circ} \mathrm{C}$, respectively $(\sim 40$ $50 \%$ transmittance).

The highest deposition temperature and time were taken as $50^{\circ} \mathrm{C}$ and $19 \mathrm{~h}\left(\right.$ at $\left.30^{\circ} \mathrm{C}\right)$ for upper limit of the parameters, respectively. Metal xanthates are known to decompose beyond these limits. Nickel xanthates, in a similar way, decomposed at $60^{\circ} \mathrm{C}$ and $21 \mathrm{~h}$ of deposition time to give nickel oxide or sulfide as decomposition product in this study. The decrease of the transmittance with the increase of deposition time is an expected result. Since, deposition time increases the thickness of the film to a limit, which causes the film to absorb more light

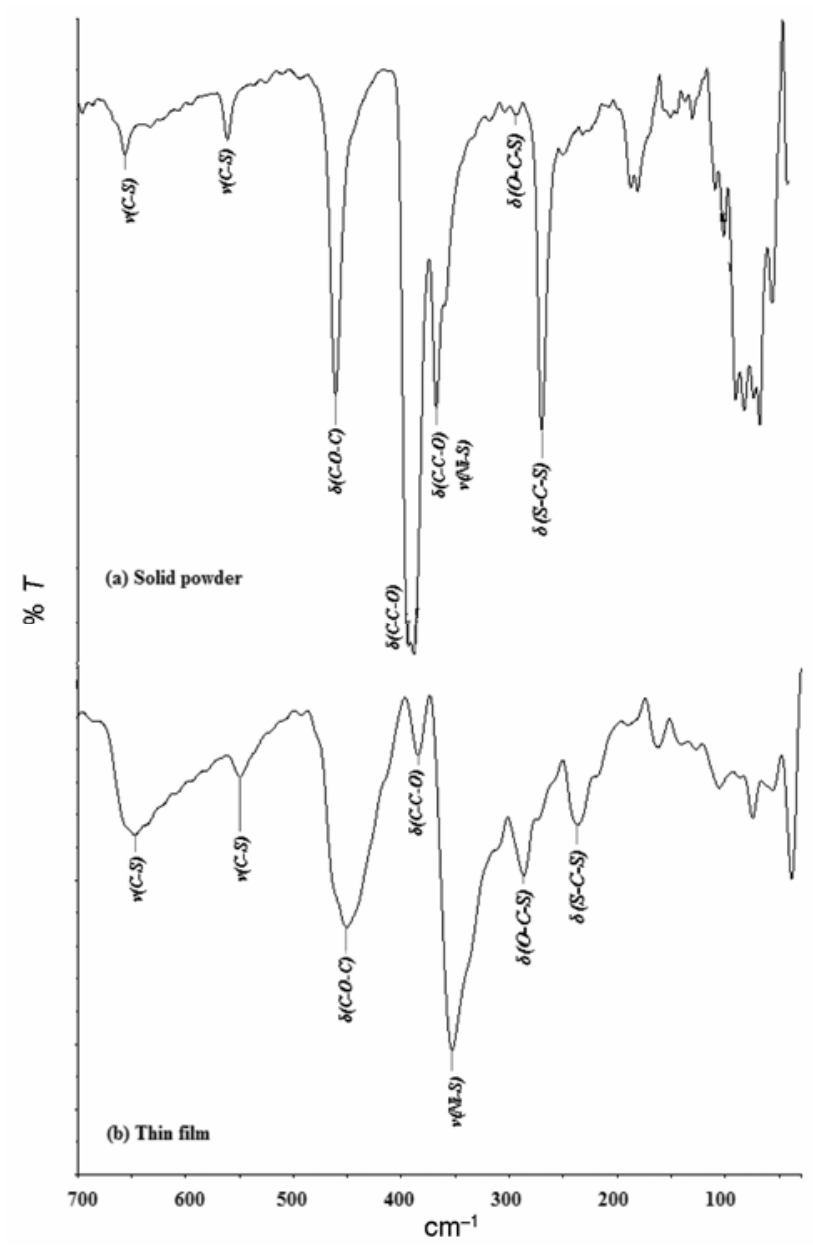

Figure 3. Nickel xanthate FIR spectrum of (a) solid powder and (b) thin film on glass substrate. falling on it; it results with a decrease of the transmittance. Moreover, the increase in the deposition temperature, also increases precipitation formation, which causes the material to flocculate, instead of floating at the surface for a while (Skoog et al 1996).

The refractive index and extinction coefficient for the films are given by the following equations (Benramdane et al 1997):

$$
\begin{aligned}
& n=\frac{(1+R)}{(1-R)}+\sqrt{\frac{4 R}{\left(1-R^{2}\right)}-k^{2}}, \\
& k=\frac{\alpha \lambda}{4 n} .
\end{aligned}
$$

Refractive indexes were affected by deposition temperatures at 30,40 and $50{ }^{\circ} \mathrm{C}$, which were calculated as 2.55 , 2.67 and $3.53(550 \mathrm{~nm}$ wavelength), respectively (figure 6). In a similar way, the extinction coefficients were measured as $0.023,0.025$ and 0.082 at temperatures 30 , 40 and $50{ }^{\circ} \mathrm{C}$, respectively. This result is not surprise for researcher. $\mathrm{Xu}$ and friends too, produced $\mathrm{ZnO}$ thin films using sol-gel method and observed that refraction index has been increased from 1.90 up to 1.98 with the increase in film thickness from 100 to $350 \mathrm{~nm}$. They argued that this is due to the concentration on the structure and optical scattering also could rise (Cruz et al 2007). The optical bandgap energy $\left(E_{\mathrm{g}}\right)$ was determined from the absorption spectra of the films using the following equation (Pejova et al 2004; Kasap et al 2006; Cruz et al 2007; Moualkia et al 2009; Liu et al 2010; Xu et al 2011):

$$
(\alpha h v)=A\left(h v-E_{\mathrm{g}}\right)^{n}
$$

where $A$ is a constant, $\alpha$ the absorption coefficient, $h v$ the photon energy and $n$ a constant, which is equal to $1 / 2$ for the direct bandgap semiconductor. The plot of $(\alpha h v)^{2}$ vs $h v$ is drawn in figure 7 .

The bandgaps $\left(E_{\mathrm{g}}\right)$ of the films estimated from the plots of $(\alpha h v)^{2}$ vs $h v$ as $3.91,3.90$ and $3.96 \mathrm{eV}$ depending on the film thicknesses obtained at different deposition temperatures of 30,40 and $50{ }^{\circ} \mathrm{C}$, respectively. The film thicknesses were changed between $622.7-913.2 \mathrm{~nm}$ by increasing deposition temperature between 30 and $50^{\circ} \mathrm{C}$. Both electrical and optical band widths of a material are correlated with the magnitude of columbic interactions. To be more precise, the size of atoms and electronegativity values are the two most important factors, affecting band width. Band width of a material is expected to get higher, when the atoms get smaller, bonds getting stronger and with higher electronegativity of the atoms. Although there are some exceptions, nitrides and oxides, which are the elements from III-V groups of periodic table, are generally known with their high optic band ranges. The high optic band width of the organometallic 

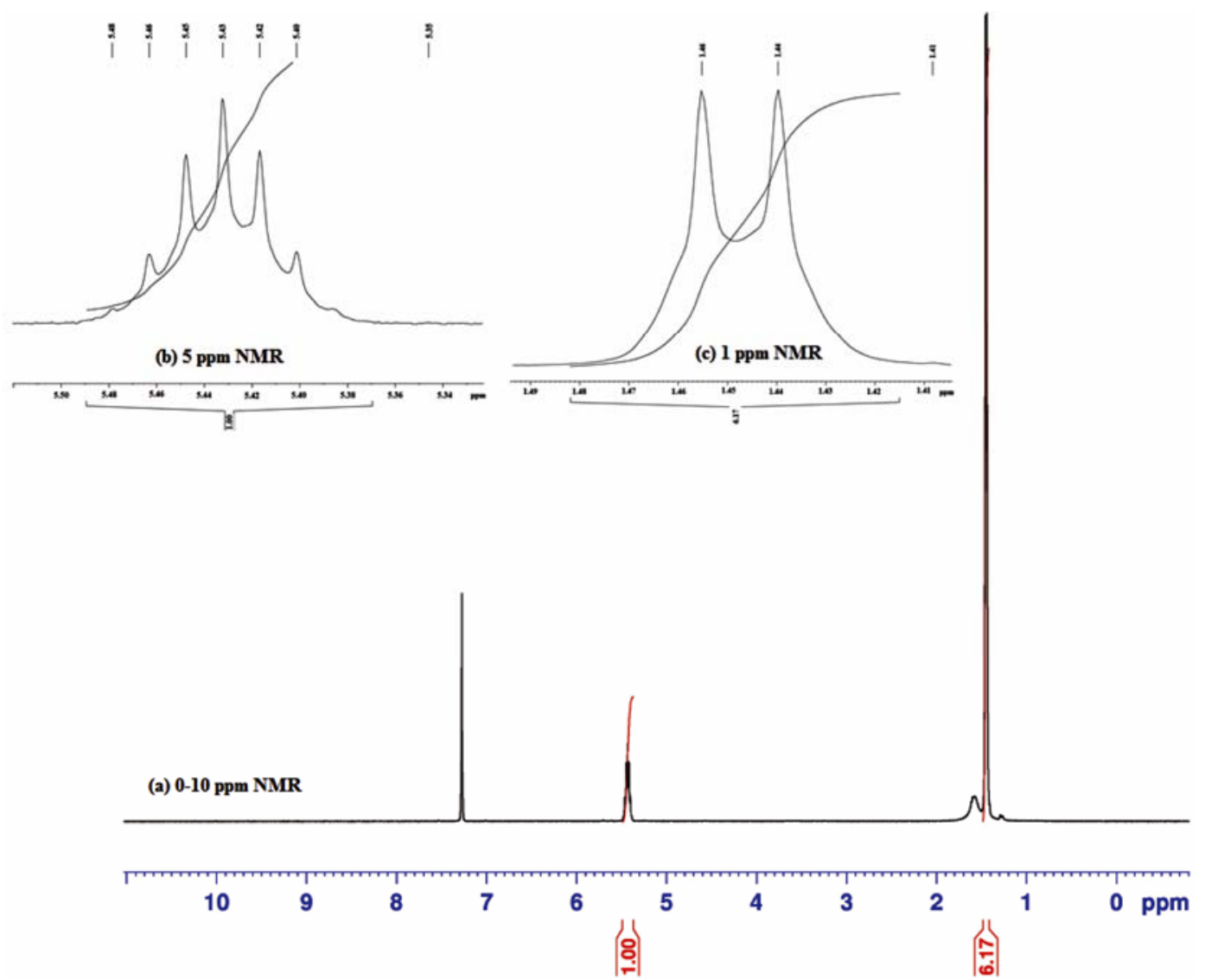

Figure 4. Nickel xanthate thin film of ${ }^{1} \mathrm{H}-\mathrm{NMR}$ at (a) $0-10$, (b) 5 and (c) $1 \mathrm{ppm}$.
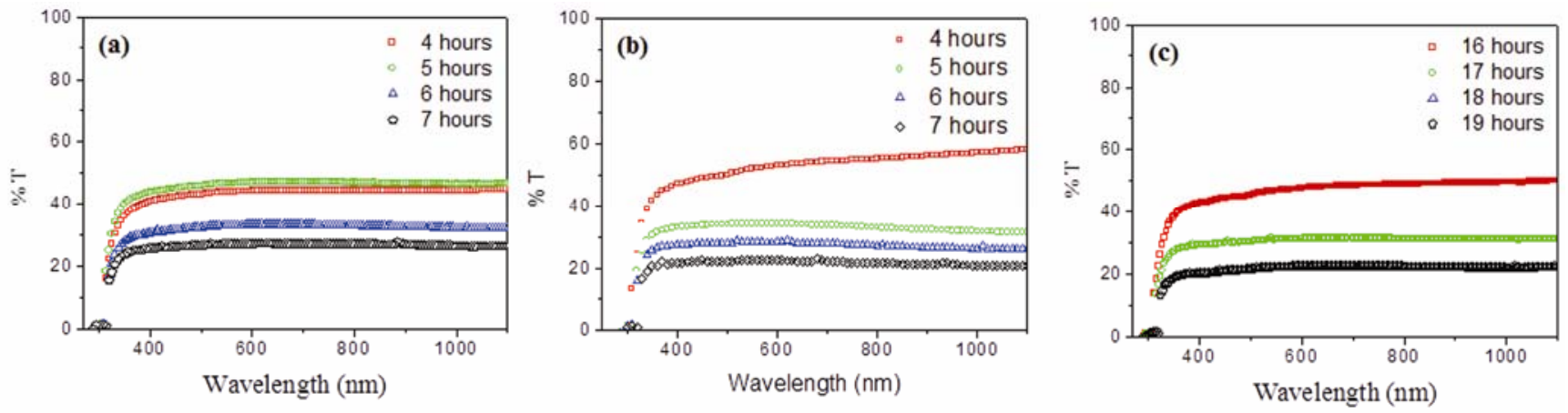

Figure 5. Change of $T \%$ and $R \%$ with wavelength at various deposition times: (a) $t=50$, (b) $t=40$ and $(\mathbf{c}) t=30{ }^{\circ} \mathrm{C}$.

compound used in our study is in line with the literature, since it is formed by small atoms with high electronegativity (Kirschman 1999). The reason for the optic band increase parallel to film thickness is the substantive amount of electronegative atoms joining to the structure with the increase in the thickness, although the structure is in crystal form. This fact has led to the increase in the optic bandgap.

It was found that the film thicknesses were increased nearly linearly with increasing deposition temperature, whereas the bandgap of the films decreased with increasing film thickness as expected (figure 8). On the other hand, relative resistivity did not increase with film thickness, which was in line with the literature (Blood and Orton 1992).

The resistivity of the films was determined by fourpoints measurements of the films using the following relation (Krulevitch et al 1996):

$$
\rho=\frac{n W V}{\ln 2 I}(W<<s)
$$

where $W$ is the film thickness, $V$ the voltage and $I$ the current. The resistivity was measured in dark and at room 

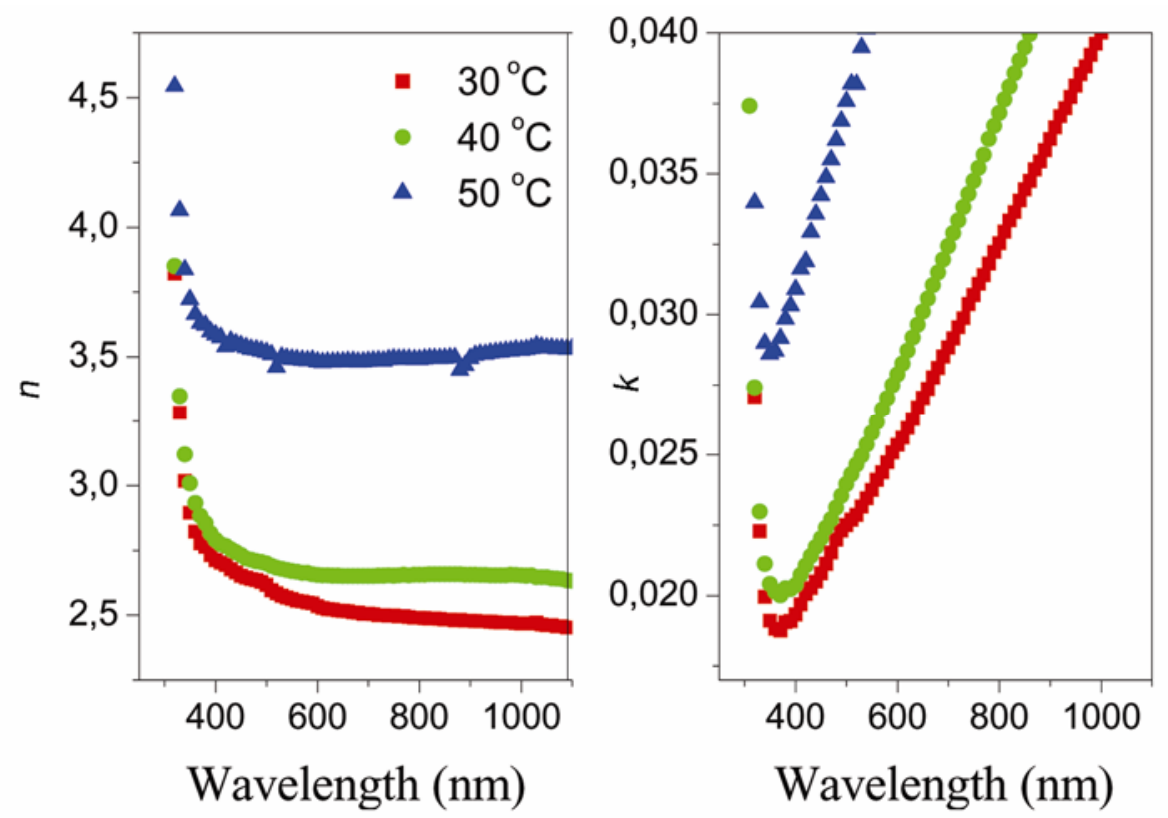

Figure 6. $n-k$ graphic according to deposition temperature.
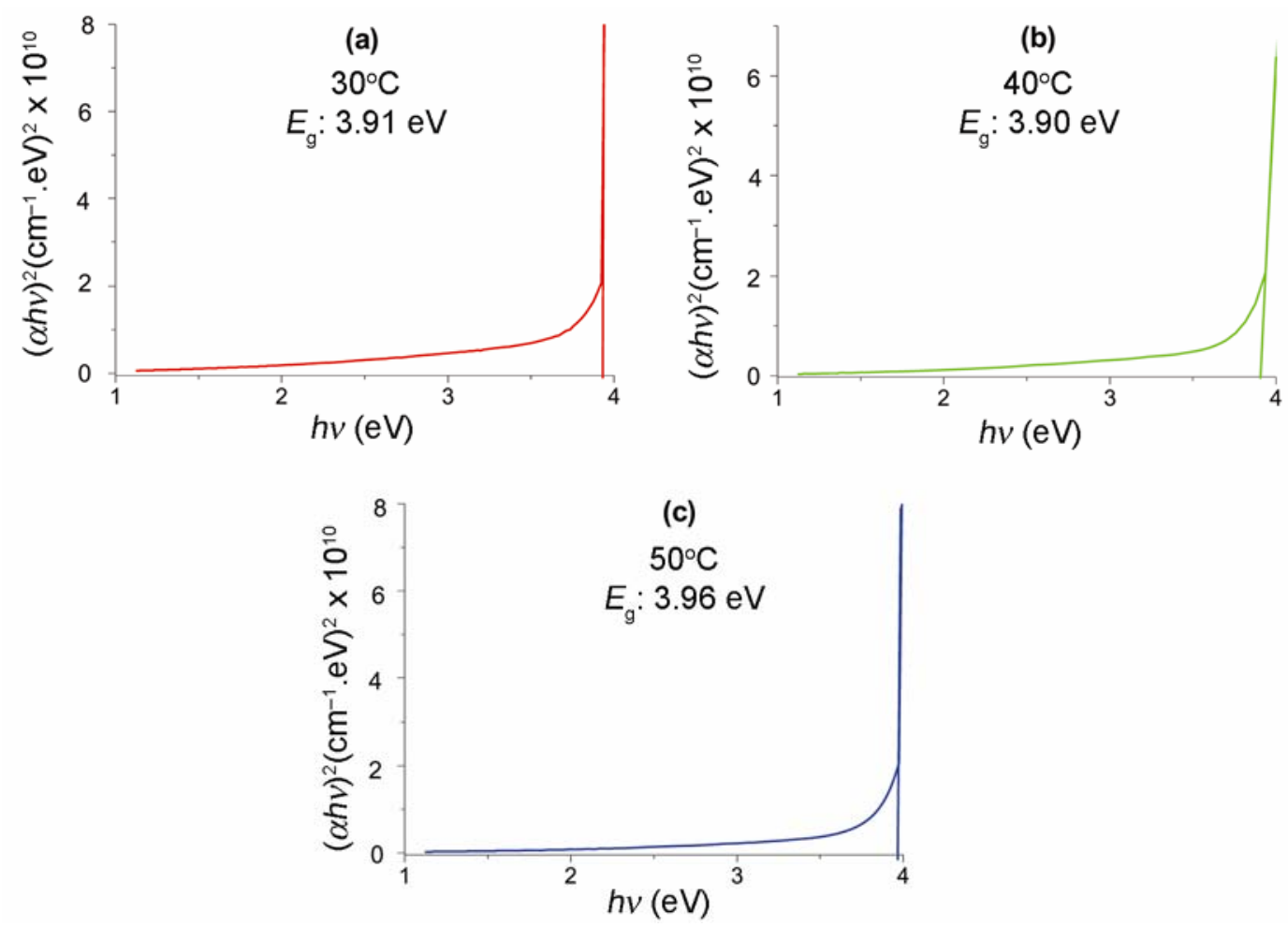

Figure 7. Plot of $(\alpha h v)^{2}$ vs $h v$ depending on deposition temperature.

temperature. In the measurements, the distance between the probes $(s)$ was in a few millimeters, whereas the film thickness was in nanometer scale. The resistivities of the films were measured as $62.57,71.03$ and $90.66 \Omega \cdot \mathrm{cm}$ for the film thicknesses $622 \cdot 7,664.9$ and $913.2 \mathrm{~nm}$, respectively.
The resistivity of the films deposited increased with the film thickness as can be seen from the plot of film thickness vs resistivity (figure 9) although, Moualkia et al (2009) and Kasap Capper (2006) predicted that the film thicknesses between 250 and $900 \mathrm{~nm}$ were slightly 


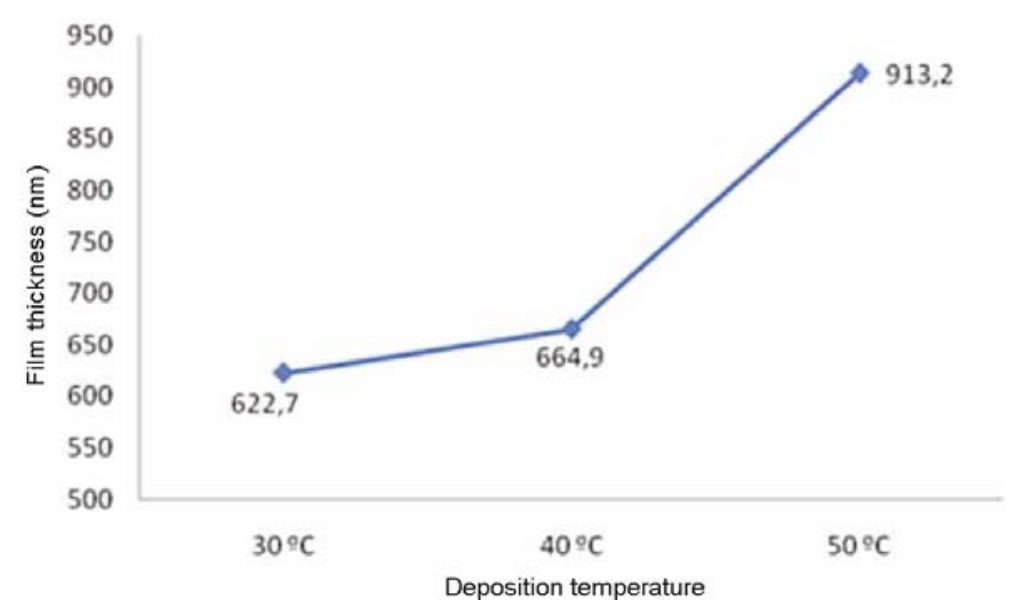

Figure 8. Film thickness-deposition temperature.

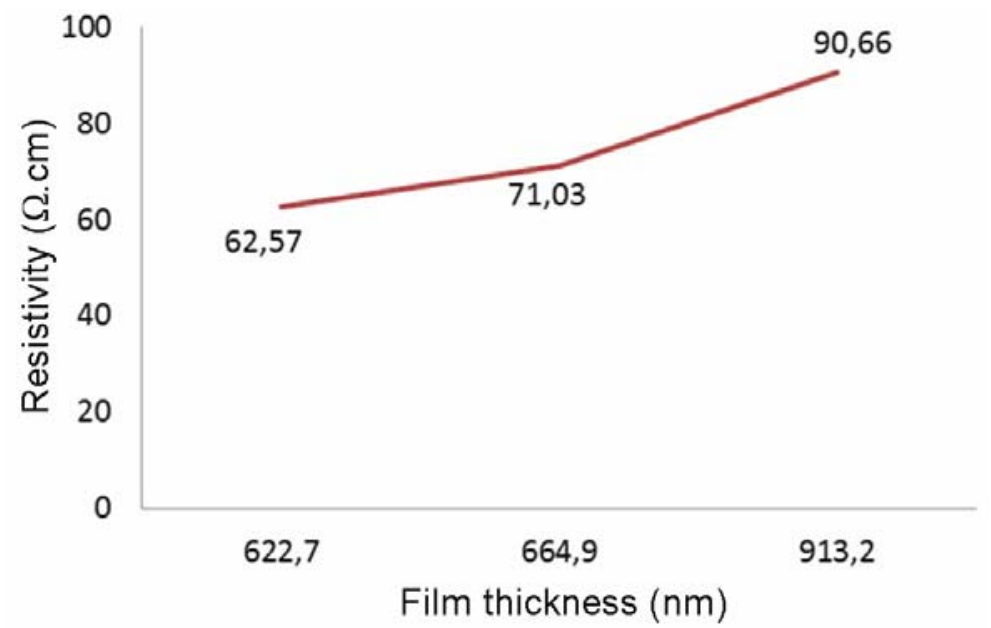

Figure 9. Resistivity of films according to film thickness.

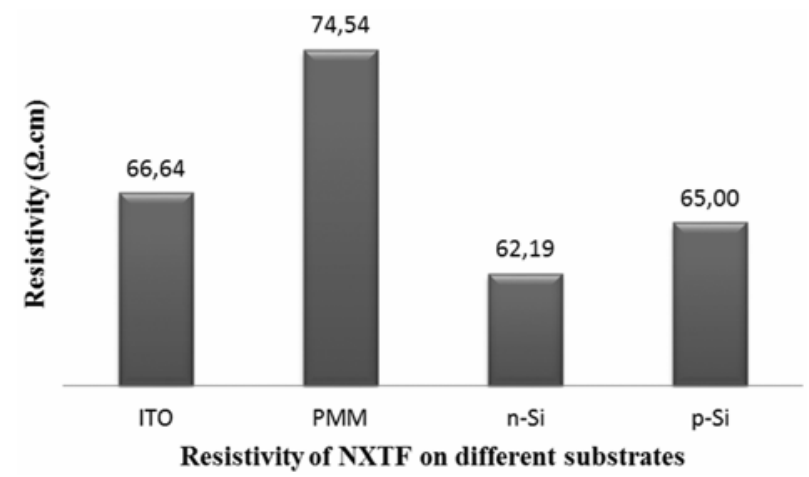

Figure 10. Resistivity of NXTF on different substrates.

affected by the resistivity of the film (Taş 2003; Ivanov 2004).

Thin fims were also produced on $n$-silicium, $p$ silicium, poly(methyl methacrylate) and indium tin oxide as different substrates in this work. The film resistivity on these substrates were found to be different than commerical glass studied previously. The resistivities of the poly(methyl methacrylate) (PMM), indium tin oxide (ITO), $n$-silicium ( $n$-Si) and $p$-silicium $(p$-Si) substrates were measured as $74.54,66 \cdot 64,62 \cdot 19$ and $65 \cdot 00 \Omega \cdot \mathrm{cm}$ at the optimized parameters of deposition time and temperature, respectively (figure 10). NXTF deposited on PMM substrates had the highest resistivity, whereas NXTF deposited on $n$-Si had the lowest resistivity (Singh et al 1991; Krulevitch et al 1996; Bakkaloğlu et al 1998).

SEM images of the film given by figures 11(a-d). SEM images show that nickel xanthate grains are regularly stacked when solid powder was compressed with $10 \mathrm{kPa}$. SEM photo shows that the nickel xanthate thin film had different images at 5 and $10 \mu \mathrm{m}$. SEM image of thin film was very different than compressed solid powder. The grains of solid powder were at micron size, whereas the grains of the film were at nanometer size. SEM images of the thin film were similar to a stressed network system. 

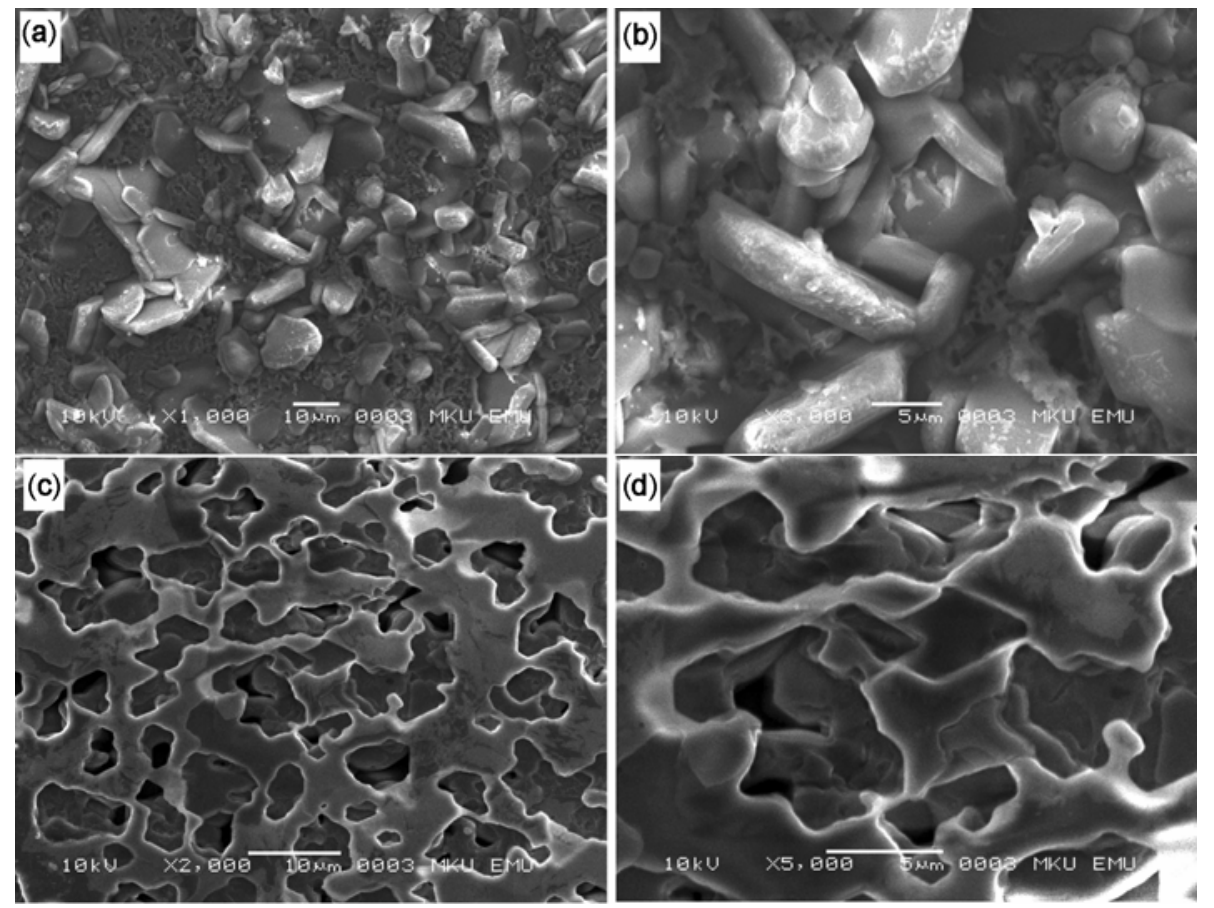

Figure 11. Nickel xanthate pellet compressed by solid powder: (a) $10 \mu \mathrm{m}$ and (b) $5 \mu \mathrm{m}$.

Nickel xanthate thin film on glass substrate: (c) $10 \mu \mathrm{m}$ and (d) $5 \mu \mathrm{m}$.

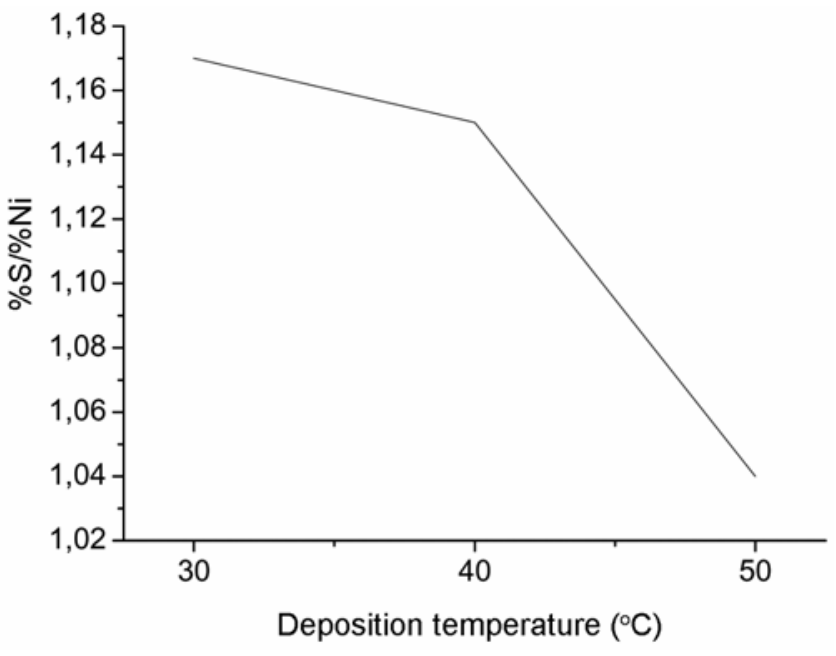

Figure 12. Sulfide and cobalt elemental ratio according to deposition temperature.

The results of elemental analysis were calculated using the ratio of sulfide and copper according to EDX data. The ratio of sulfide and nickel is shown in figure 12. Sulfide/nickel ratio has changed with deposition temperature. Measured ratios of sulfide and nickel were 1.17, 1.15 and 1.04 according to deposition temperature, whereas the theorical ratio of sulfide and nickel was approximately 1.09 in the cobalt xanthate molecule. The elemental results were not close to the theoretical value. This shows that the nickel cation bonds with one xanthate molecule, unlike stated in the literature (Watt and McCormick 1965). According to Watt and McCormick (1965), two potassium ethyl xanthate ligands have been formed in ethyl xanthate with nickel cation. They argued that their nickel complex was $\mathrm{Ni}\left(\mathrm{CH}_{3} \mathrm{CH}_{2} \mathrm{OCS}_{2}\right)_{2}$, when they have examined nickel xanthate by IR analysis.

\section{Conclusions}

Iron isopropyl xanthate thin film was prepared first time on glass, poly(methyl methacrylate), indium tin oxide, $n$ silicon and $p$-silicon substrate by ion-ion mechanism. The optimum parameter was determined as $4 \mathrm{~h}$ and $50^{\circ} \mathrm{C}$ for deposition time and temperature, respectively. The relation of some chemical properties with changing deposition temperatures at 30,40 and $50{ }^{\circ} \mathrm{C}$ were examined. The refractive indexes were found to be $2 \cdot 55,2 \cdot 67$ and 3.53 (550 $\mathrm{nm}$ wavelength) for the deposition temperatures at 30,40 and $50{ }^{\circ} \mathrm{C}$, respectively. The extinction coefficients were measured as $0.023,0.025$ and 0.082 at temperatures 30,40 and $50{ }^{\circ} \mathrm{C}$, respectively. The bandgaps $\left(E_{\mathrm{g}}\right)$ of the films were found to be $3.91,3.90$ and $3.96 \mathrm{eV}$ for the deposition temperatures at 30, 40 and $50{ }^{\circ} \mathrm{C}$, respectively. The film thicknesses were changed between 622.7 and $913.2 \mathrm{~nm}$ by increasing the deposition temperature between 30 and $50{ }^{\circ} \mathrm{C}$. The resistivities of the films were measured as $62.57,71.03$ and $90.66 \Omega \cdot \mathrm{cm}$ for the film thicknesses $622.7,664.9$ and $913.2 \mathrm{~nm}$, respectively. The resistivities of the poly(methyl methacrylate) (PMM), indium tin oxide (ITO), $n$-silicium ( $n$-Si) and $p$ silicium ( $p$ - $\mathrm{Si}$ ) substrates were measured as 74.54, 66.64, 62.19 and $65.00 \Omega \cdot \mathrm{cm}$ at the optimized parameters of deposition time and temperature, respectively. SEM 
images of thin films gave idea about their resistivity and refractive index. The film deposited on $n$-Si had lower resistivity than the other substrates. We can conclude that this newly prepared and examined thin film can be further investigated to be a new material, which may be useful for solar cells, detectors or sensors.

\section{Acknowledgments}

This study was supported by Erciyes University.

\section{References}

Armitage G C 2004 Periodontol 349

Bakkaloğlu Ö F, Karahan İ H, Efeoğlu H, Yıldırım M, Çevik U and Yoğurtçu Y K 1998 J. Magn. Magn. Mater. 190193

Benramdane N, Murad W A, Misho R H, Ziane M and Kebbab Z 1997 Mater. Chem. Phys. 48119

Bertram U and Bodmeier R 2006 Eur. J. Pharm. \& Biopharm. 63310

Blood P and Orton J W 1992 The electrical characterization of semiconductors: majority carriers and electron states (London: Academic Press) p. 734

Cristol S J and Seapy D G 1982 J. Org. Chem. 47132

Cruz J S, Pérez R C, Delgado G T and Angel O Z 2007 Thin Solid Films $\mathbf{5 1 5} 5381$

Cullity B D 1967 Elements of X-ray diffraction (Londra: Addison-Wesley Publishing Company, Inc) 3rd edn, p. 99

Erdik E, Obalı M, Yüksekışık N, Öktemer A and Pekel T 2007 Denel Organik Kimya, Gazi Kitapevi, 4th edn, Ankara, p. 1226

Fehér A, Urbán E, Erős I, Szabó-Révész P and Csányi E 2008 Int. J. Pharm. 35823

Fischer R A, Weiß J and Rogge W 1998 Polyhedron 171203

Fornasiero D and Montalti M and Ralston J $1995 \mathrm{~J}$. Col. Int. Sci. 172467

Gao H J, Bian Z X, Chen H Y, Xue Z Q and Pang S J 1997 Chem. Phys. Lett. 272459

Ghaedi M 2007 Spectrochim. Acta Part A 66295

Görgülü A O 2002 1-3-dikloropropan-2-ol'ün Tersiyer Amin Türevlerinden Ksantatların Sentezi ve Geçiş Metal Kompleksleri, Doktora Tezi, Firat Üniversitesi, Elazı ğ

Grassi M, Soares D A W, de Queiroz A A A, Bressiani A H A and Bressiani J C 2004 Mater. Sci. Eng. B112 179

Haiduc I, Semeniuc R F, Campian M, Kravtsov V C, Simonov Y A and Lipkowski J 2003 Polyhedron 222895

Hitchman M L and Jensen K F 1993 Chemical vapor deposition: principles and applications (San Diego: Academic Press)

Ivanov A V 2004 Russ. J. Coord. Chem. 30480

Jeong Y M, Lee J K, Ha, S C and Kim S H 2009 Thin Solid Films $\mathbf{5 1 7} 2855$

Kasap S and Capper P 2006 Springer handbook of electronic and photonic materials, pp. 19-44.

Kirschman R 1999 High-temperature electronics (NY: IEEE Press)

Krulevitch P, Lee A P, Ramsey P B, Trevino J C, Hamilton J and Northrup M A 1996 J. Microelectmech. Syst. 5270
Laespada M E F, Perez J L and Cordero B M 1993 Analyst 118209

Leja J 1982 Surface chemistry of froth flotation (New York: Plenum Press)

Liu F, Lai Y, Liu J, Wang B, Kuang S and Zang Z $2010 \mathrm{~J}$. Alloys Compd. 493305

Manzoori J L and Bavili-Tabrizi A 2002 Anal. Chim. Acta 470 215

McCool J C 1954 Method of preparing alkali metal xanthates United States Patent Office, 2678939, 18 May

Miller J D, Li J, Davidtz J C and Vos F 2005 Miner. Eng. 18 855

Moualkia H, Hariech S and Aida M S 2009 Thin Solid Films 5181259

Musetha P L 2006 The use of metal complexes to deposite metals calconide thin films and nanoparticles, Doctorate Thesis, University of Zululand, South Africa

Oliveria C R and Rubio J 2009 Int. J. Miner. Process 9021

Paleologos G D L and Tzouwara-Karaynni S M 2002 Anal. Chim. Acta 458241

Pejova B, Grozdanov I and Tanusevski A 2004 Mater. Chem. Phys. 83245

Pellizzeti E and Pramauro E 1985 Anal. Chim. Acta 1691

Pramauro E, Prevot A B 1995 Pure Appl. Chem. 67551

Reyes J C F R and Teplyakov A V 2007 Chem. Eur. J. 139164

Rubio J, Capponi F, Rodrigues R T and Matiolo E 2007 Int. J. Miner. Process. 8441

Ruffle J A, Knighton G J and Spencer E Y 1953 Process for the production of sodium isopropyl xanthate, Canadian Intellectual Property Office, CA 489807, 20 January

Sahar G A, Soomro G A and Bahnger M I 2004 J. Chem. Soc. Pak. 26143

Shankaranarayana M L and Patel C C 1961 Can. J. Chem. 39 1633

Singh M, Vijay Y K and Jain I P 1991 Int. J. Hydrogen Energ. 16101

Skoog D A, West D M and Holler F J 1996 Fundamentals of analytical chemistry (USA: Saunders College Publishing) 7th edn, pp 80-96

Stalikas C D 2002 Trends Anal. Chem. 21343

Taş H 2003 Coordination polimerization of cyclic ethers by metal xanthates and carbamates, Yüksek Lisans Tezi, ODTÜ, Polimer Bilimi ve Teknolojisi Bölümü, Ankara

Valdivieso A L, López A A S, Escamilla C O and Fuerstenau M C 2006 Int. J. Miner. Process. 8127

Watt G W and McCormick B J 1965 Spectr. Acta 21753

Wilhelm H 1929 Process of manufacturing sodium xanthates, United States Patent Office, 1701264, 28 November

Wilhelm H 1935 Process for preparing xanthates, United States Patent Office, 2024925, 17 December

Wilhelm H, Ramage W D and Bender H, Preparing of making xanthates United States Patent Office, 2024924, 17 December

Xu K, Ding W and Chen Y 2004 J. Chem. Cryst. 10665

Xu L, Li X, Chen Y and Xu F 2011 Appl. Surf. Sci. 2574031

Zelmon D E, Gebeyehu Z, Tomlin D and Cooper T M 1998 Mater. Res. Soc. $\mathbf{5 1 9} 395$

Zohir N, Bouhenguel M and Djebaili A E 2009 J. Min. \& Mat. Char. \& Eng. 8469

Zohir N, Bouhenguel M and Djebaili A E 2009 J. Min. \& Mat. Char. \& Eng. 8469 